\title{
Local news availability does not increase pro-social pandemic response \\ 2
}

Sean Fischer*1

${ }^{1}$ Annenberg School for Communication, University of Pennsylvania

September 16, 2020

*Corresponding author: Sean Fischer (sean.fischer@asc.upenn.edu; @seanafischer). This work has been improved through helpful comments from Yphtach Lelkes, Nikki Usher, and Joshua Benton. 


\begin{abstract}
Local media provide a bevy of pro-social and civic benefits because they provide essential information about peoples' local communities. The COVID-19 pandemic has created the conditions to test whether these conclusions can be extended beyond traditional political or civic domains, as the crisis had a particularly idiosyncratic spread across the United States. In a period of competing information and regulations, as well as rampant partisanship, a high volume of local media in an area should have led to a more pro-social response to the pandemic, as local residents had greater opportunities to learn about the risks specific to their communities and what their local and state officials were asking them to do. In particular, those with more local news available should have stayed home more and gone out for unnecessary travel less. I test this theory by combining county mobility data with counts of the local newspapers available in each county and other local demographic measures. After controlling for these other demographics and addressing potential confounding through weighting, I find no substantive effect of local newspaper volume on mobility change. This lack of a causal effect of local news availability on pro-social behavior uptake has implications for how we think about local media's role and efficacy in their communities.
\end{abstract}

One of the challenges in the American response to the COVID-19 pandemic has been the local variation in the virus's spread. While New York and other Northeastern states faced the brunt of the virus's impact in March and April 2020, the American South became the national epicenter in June and July 2020. Even inside a single state, the virus's spread and effects have varied between regions. Complicating matters, the federal government has not provided unifying guidance, leaving each state and locality to develop its own restrictions and regulations, heightening the pandemic's geographic idiosyncrasy. As such, most Americans have taken up following news about the pandemic at the local level [1], which has meant turning to and placing increased trust in local news outlets' information about the pandemic and how to respond to it $[1,2]$. In fact, much has been made about how local news is an optimal pathway for combating misinformation about the pandemic $[3,4]$.

However, local news outlets have been disappearing across the United States for more than a decade [5,6]. Today, almost 200 counties have no newspapers and more than 1,400 have only one newspaper [5]. In the current moment, that means that some counties are potentially better positioned to follow and respond to the pandemic by adopting the types of responses advocated for by health experts, such as mask-wearing, hand washing, and social distancing. This study tests whether counties with healthier local news economies responded in a more pro-social manner than those with less healthy local news economies. 
It is possible that a positive association between local news availability and the uptake of pro-social health behaviors does exist, as other pro-social effects of local news availability are well documented. For example, newspaper closures lead to declines in the rates at which people contact public officials, boycott products or services, join civic groups, and act as an officer for the groups to which they belong [7]. Similarly, the disappearance of local newspapers leads to less accountability of local governments [8]. Exacerbating the accountability issues, declines in local political news have are associated with declines in the political knowledge necessary to evaluate politicians and reductions in voter turnout $[9,10]$.

In all of these examples, local newspapers promote pro-social behavior by making it easier for the mass public to learn about politics. This accountability function of the local news is a byproduct of providing citizens with information about local politics and government to which they would otherwise not have access. The same could be true about COVID-19 and how best to respond, given that it is also an unfamiliar topic for which there is a sizable information asymmetry between elites and the mass public and that the pandemic and government responses have been locally idiosyncratic.

To test whether local news affects the adoption of pro-social responses to COVID-19, I take advantage of differences in news availability between counties. By leveraging this variation in the volume of local newspapers available in a county, I generate an estimate of the causal effect of the volume of local news on changes in travel for retail and recreation and time spent at home for thousands of American counties. An initial set of models accounting for county-level pandemic features and local demographics shows no substantive local-news effect.

Even so, the effect of local-news availability may be contingent on citizens becoming aware that there is a crisis about which they need to learn more. For each county, I identify two such moments: March 11 th, the day that Tom Hanks announced his COVID-19 diagnosis, the NBA began canceling games, and the World Health Organization declared COVID-19 a pandemic, and the day that their state-issued stayat-home orders. To account for the possibility that these events affected information-seeking behavior, I estimated a model controlling for a selection of pandemic features and county-level demographics, as well as the interaction between newspaper volume and the period from which an observation was drawn. These models show that following these events, counties with more local news did not have significantly greater mobility change. 


\section{Results}

\section{Main Effect of Newspaper Volume}

The simplest models I estimated find the expected relationship between the volume of local newspapers available and pro-social behaviors, decreases in retail and recreation travel and increases in spending time at home, to be significant. A one-standard-deviation increase in the number of newspapers available in a county is associated with a 0.083 standard-deviation increase in the percentage point change in staying at home $\left(95 \% \mathrm{CI}=(0.044,0.12), \mathrm{p}=2.96 \times 10^{-5}\right)$. Alternatively, the same one-standard-deviation increase in the number of newspapers is associated with a 0.11 standard-deviation decrease $(95 \% \mathrm{CI}=(-0.16$, -0.063), $p=4.65 \times 10^{-6}$ ) in the percentage-point change from baseline in travel for recreation or retail purposes. Full details can be found in Model 1 of Tables 1 and 2.

However, we should reasonably expect county-wide movement behavior during the COVID-19 pandemic to be affected by the severity of any outbreak in the county. As such, the second set of models I estimated included controls for the number of cases and deaths related to COVID-19 in each county, an indicator for whether the county's governor had issued a statewide stay-at-home order, a measure of how far into the 76-days the observation came, and the interaction between these last two variables.

Even controlling for these pandemic features, there is still evidence of a significant relationship between local news volume and pro-social behavior adoption. As we can see in Figure 1, the one-standard-deviation change in newspaper count, according to this model, produces a 0.035 standard-deviation increase in the percentage change from baseline for staying at home $(95 \% \mathrm{CI}=(0.0066,0.063), \mathrm{p}=0.016)$. Similarly, the relationship between newspaper count and travel for recreation or retail purposes is also still significant and in the expected direction $(\beta=$ $-0.050,95 \% \mathrm{CI}=(-0.081,-0.019), \mathrm{p}=0.0014)$. The associated details can be found in Model 2 of Tables 1 and 2.

Do these relationships hold while controlling for county demographic and structural features, such as partisan lean? To answer this question, I re-estimated the models, now including controls for county demographic and structural features. Results from these models are visualized in Figure 2. With these additional controls, the estimated relationship changes direction for both staying at home $(\beta=-0.018,95 \%$ $\mathrm{CI}=(-0.029,0.0061), \mathrm{p}=0.0028)$ and retail or recreation related travel $\left(\beta=0.021,95 \% \mathrm{CI}=(0.011,0.029), \mathbf{p}=7.73 \times 10^{-6}\right)$. Full results are in Model 3 of Tables 1 and 2.

Beyond these flips, what we see in both contexts is that a few factors have strong relationships with changes in behavior. For both, the presence of a stay-at-home order has the largest effect (Residential: $\beta=$ 
$1.06,95 \% \mathrm{CI}=(0.98,1.14), \mathrm{p}<2 \times 10^{-16}$; Retail \& Recreation: $\beta=-1.10$, $\left.95 \% \mathrm{CI}=(-1.19,-1.01), \mathrm{p}<2 \times 10^{-16}\right)$. Time, measured in days, is also a strong predictor of mobility change in both cases. A one-standard deviation jump forward in time is associated with a 0.96 standard-deviation increase in staying home $\left(95 \% \mathrm{CI}=(0.90,1.03), \mathrm{p}<2 \times 10^{-16}\right)$ and a 0.92 standard-deviation decrease in recreation-and-retail travel $(95 \% \mathrm{CI}=(-$ 0.96, -0.87), $\mathrm{p}<2 \times 10^{-16}$ ). However, we see that the interaction between these two variables is large and in the opposite direction of the individual main effects $\left(\beta_{\text {Residential }}=-1.26,95 \% \mathrm{CI}_{\text {Residential }}=(-1.35,-1.17)\right.$, $\mathrm{p}_{\text {Residential }}<2 \times 10^{-16} ; \beta_{\text {Retail\&Recreation }}=1.40,95 \% \mathrm{CI}_{\text {Retail\&Recreation }}=$ $\left.(1.27,1.51), \mathrm{p}_{\text {Retail\&Recreation }}=2 \times 10^{-16}\right)$. This suggests that the relationship between stay-at-home orders and behavior change wanes with time.

Notably, the county's partisan lean is significantly associated with both types of mobility change (Residential: $\beta=0.083,95 \% \mathrm{CI}=(0.054$, $0.11), \mathrm{p}=1.69 \times 10^{-8}$; Retail \& Recreation: $\beta=-0.084,95 \% \mathrm{CI}=(-0.11$, 0.056), $\mathrm{p}=3.35 \times 10^{-9}$ ). These relationships are substantially larger than those between both types of mobility change and newspaper volume. These results align with the observations made elsewhere about the influence of partisanship in responding to the threat of the virus [11].

Even so, the model specifications in Model 3 of Tables 1 and 2 are likely biased by confounding. Covariates like a county's education and income levels are likely related to both the treatment, newspaper availability, and the outcomes, change in behavior. To account for this possibility, I conducted non-parametric covariate balancing propensity score weighting. I generated weights based on the time-invariant county-level covariates. This procedure reduced the average correlation between each covariate and treatment, as seen in Supplementary Figure 2.

Using the weights output from the propensity score model, I reestimated the models. Addressing potential confounding, these results are more consistent estimates of the effect of local news availability on behavior change than those produced in earlier models. Yet, as we can see in Figure 3, the estimated effects are statistically insignificant for staying at home $(\beta=0.0087,95 \% \mathrm{CI}=(-0.030,0.048), \mathrm{p}=0.66)$. But, we do observe a significant effect on traveling for retail or recreation purposes $(\beta=-0.035,95 \% \mathrm{CI}=(-0.069,-0.00081), \mathrm{p}=0.045)$. Notably, this significant effect on change in travel for retail and recreation is less than half the magnitude of the effect of partisanship ( $\beta=-0.083,95 \%$ $\left.\mathrm{CI}=(-0.11,-0.054), \mathrm{p}=9.70 \times 10^{-9}\right)$ and a small fraction of the observed effect of the presence of a statewide stay-at-home order $(\beta=-1.14,95 \%$ $\mathrm{CI}=(-1.24,-1.045), \mathrm{p}<2 \times 10-16)$. Complete specifications are reported in Model 4 of Tables 1 and 2.

Given that both analyses are sufficiently powered - power estimates indicate that the chance of a false negative is approximately 0 in both cases - the most likely conclusion is that there is no significant effect of local newspaper availability on staying home, but a small effect on 
changes in travel for retail and recreation purposes.

Of course, my operationalization of the treatment variable as the count of newspapers in a county makes a few assumptions about the nature of the hypothesized treatment effect. However, I also estimated all of the same models with two additional operationalizations of news availability. In the first, I used the standardized and centered log count of newspapers. In the second, I used a binary indicator coded to 1 if a county had any newspaper. As shown in Supplementary Tables 14 , these operationalizations do not lead to substantively different conclusions. Local news availability has no meaningful effect on behavior change in either context.

\section{Changing Effects over Time}

While modeling the effects of local newspaper volume across the entire 76-day period from February 15th, 2020, to April 30th, 2020, reveals no substantive relationship between the number of newspapers in a county and that county's change in mobility, these models do not account for the possibility that the effect of local news is moderated by other time-dependent changes in the information environment. These possible information-environment changes include changes in the reported severity of COVID-19 or the implementation of location-specific policies. To account for these possible moderation effects, I conducted a second analysis evaluating the effect of local news volume in three periods: before and up through March 11th, 2020; then from March 12th, 2020, up till a state put in place stay-at-home orders; and, then, the period following the implementation of stay-at-home orders.

Given that this analysis is effectively a difference-in-difference design, the model assumes that counties with differing numbers of local newspapers had similar trends before the changes in the information environment. To validate the parallel trends assumption, I plotted the relationship between time and change in behavior, with regression lines added for the observations up through March 11th, 2020, and those that came after, as seen in Supplementary Figure 3. As we can see, before this date, the average behavioral changes between counties with low and high amounts of local news are similar.

With this assumption met, I estimated linear models regressing daily behavior change on the interaction between the number of newspapers in a county and the period into which each observation falls, as well as the same county-level covariates included in the first set of models.

As we can see in Model 1 of Tables 3 and 4 and Panels A and B of Figure 4, the effect of local newspaper volume is significantly moderated by time in the unweighted models. In the period between March 12 and the implementation of statewide shutdowns, a one-standarddeviation increase in local newspaper volume was associated with an 
additional 0.054 standard-deviation increase in staying at home (95\% $\mathrm{CI}=(0.015,0.094), \mathrm{p}=0.0068)$. In the period between the implementation of statewide shutdowns and April 30, that same one-standarddeviation increase in local newspaper volume produced an additional 0.073 standard-deviation increase in staying home $(95 \% \mathrm{CI}=(0.028$, $0.12), p=0.0016)$. In regards to travel for retail or recreation purposes, a one-standard-deviation change in newspaper volume did not produce a statistically significant change in the period from March 12 to the implementation of statewide orders $(\beta=-0.028,95 \% \mathrm{CI}=(-0.067,0.011), \mathrm{p}$ $=0.16$ ), while the same one-standard-deviation increase in newspaper volume produced an additional 0.068 standard-deviation decrease in going out for these purposes following the implementation of statewide stay-at-home orders $(95 \% \mathrm{CI}=(-0.11,-0.029), \mathrm{p}=0.00066)$.

However, if we apply the same non-parametric covariate balancing propensity score weighting used in the prior section, the results change substantially. With this weighting, the the effect of local newspaper volume on staying home, while statistically insignificant, is actually negative in the latter two time periods (March 12 - Order: $\beta=-0.12,95 \%$ $\mathrm{CI}=(-0.26,0.017), \mathrm{p}=0.085$; After Order: $\beta=-0.12,95 \% \mathrm{CI}=(-0.27$, 0.024), $\mathrm{p}=0.10$ ). Similarly, in the period from March 12 till the implementation of statewide stay-at-home orders, the effect of local newspaper volume on travel for retail or recreation purposes changes sign from negative to positive and is statistically insignificant $(\beta=0.074,95 \% \mathrm{CI}$ $=(-0.048,0.20), p=0.24)$. Yet, in the period following the implementation of statewide orders till April 30, the effect is insignificant, but in the expected negative direction $(\beta=-0.066,95 \% \mathrm{CI}=(-0.16,0.023), \mathrm{p}$ $=0.15$ ). Full results are in Model 2 of Tables 3 and 4, with associated predictions visualized in Panels $\mathrm{C}$ and D of Figure 4.

To contextualize the estimated effects across all four models, I plotted the predicted standard-deviation change in mobility during each period for counties ranging from 0 to 40 papers in Figure 4 . Even when the interaction effects are significant (Panels A and B), the effects' substantive impacts are still small. A change from 0 to 40 papers in a county - a change of over 11 standard deviations in the number of papers) in the period after statewide orders only produces a predicted change in staying home of about 0.24 standard deviations. For travel for retail or recreation purposes, the same change in the same period only leads to a decrease of 0.30 standard deviations in mobility based on the unweighted model.

These results do not substantively change if I operationalize the treatment variable as a binary indicator for the presence of any local newspapers or as the log of the count of newspapers in a county, as shown in Supplementary Tables 5-8. 


\section{Discussion}

Local news has the potential to generate a positive effect on the adoption of pro-social responses to the COVID-19 pandemic. To test whether such effects have materialized, I analyzed the publicly available mobility reports provided by Google regarding staying home and traveling for retail and recreation purposes. Models regressing change in mobility on the volume of local news, pandemic-related features, and structural and demographic features showed that, when accounting for potential confounding, there was no substantive relationship between the number of newspapers in a county and that county's mobility change. Even considering variation in the effect over distinct periods, while still accounting for potential confounding, does not produce evidence supporting the hypothesis that an abundance of local news increased pro-social response uptake. Operationalizing treatment as a binary indicator of the presence of any local newspaper does not change the substantive results.

These results are normatively concerning because they suggest that the pro-social impact of local news may be limited. While local news promotes healthy civic engagement, such as by promoting voter turnout $[9,10]$, it does not appear to be counteracting the partisan response to the COVID-19 pandemic, which is likely due to differences in how partisan media and elites from both parties framed the severity of the virus [12,13], as well as the activation of mass partisan animus as health behaviors became politicized [14]. As such, my results point towards a substantial limitation for local news to promote pro-social behavior in politically polarized contexts. The implications of such a limitation are concerning, given the possibility of partisan media and elites politicizing essential civic issues, such as voting by mail [15], thus turning attitudes and behavior related to these issues into opportunities to signal one's partisan identity. If issues become strongly politicized and polarized, it is not clear that local media can undo such positiontaking.

But, should I have expected to find an effect in the first place? While local news availability leads to more pro-social civic behavior, such as voting, the comparison to pro-social COVID-19 response may not fit. One could argue that COVID-19 is a singular national-level crisis and disaster covered across all levels of journalism, while local elections are highly idiosyncratic and are likely to only be covered by local outlets. However, positioning the COVID-19 pandemic at the opposite binary of local elections would be misplaced.

To begin with, this assumption inaccurately characterizes local elections. Local elections are unique cases of a much larger national event. Local elections are specific instances of the two national parties competing. When local news disappears, citizens turn to national media and partisan heuristics to make their decisions, leading to less split- 
ticket voting [16]. Similarly, the expansion of political coverage brought about by the Internet has led to an increase in national considerations when voting in local elections [17]. Both of these results demonstrate how local elections exist along a local-national spectrum. Local news leads citizens to consider the local context of the election, but it is an oversimplification to argue that local elections are truly low-information affairs.

Furthermore, this strong differentiation between local-election coverage and COVID-19 coverage also inaccurately characterizes the pandemic. COVID-19 is not a monolithic story. While there is a strong national element playing out, local communities have had a distributed and asynchronous experience of dealing with the pandemic. These differences have manifested in differing regulations across states, counties, and municipalities regarding staying at home, face coverings, and testing [18]. As such, local contexts are highly important and local news sources have much to offer, which both Democrat and Republican politicians have indicated [19].

That being said, one could argue that a high degree of choice does not matter inside a county or community. As long as there is a pathway, citizens could access helpful and necessary information. Yet, I account for this possibility through an additional operationalization of news availability that codes news availability as a binary variable, coded to 1 when a county has any number of newspapers and 0 when they have no newspapers. This operationalization produces substantively similar results in both the stay-at-home and travel for retail and recreation contexts: having any newspaper at all does not lead to behavior change.

Similarly, one could argue that news consumers are more likely to turn to TV news, especially local TV news, during a crisis. Nielsen data lends credence to this theory; local TV news viewership was up about $7 \%$ in major media markets, with greater effects among younger viewers [20]. Larger than that, the major broadcast evening-news programs saw a $42 \%$ year-over-year increase in viewers during the week of March 16th [21] and cable news saw viewership sore to record or near-record highs in April [22]. Even so, The New York Times report on Internet audience behavior indicates that major market newspapers were regularly experiencing audience growth above 100\% in March 2020 compared to February 2020 [2]. Without absolute audience counts, comparing growth rates could lead to false perceptions of absolute audience size. Yet, these reports suggest that, behaviorally, Americans turn their attention to multiple local news and information pathways simultaneously, meaning that newspaper availability should be a relevant factor in communities' pandemic responses.

Beyond these theoretical concerns, it is important to consider the practical limitations of this study. Causal inference with observational data is notoriously difficult. However, one of the principal concerns with 
regression estimates in such cases is that unobserved confounders will account for observed significant relationships. In this case, though, the expected relationship disappears when just controlling for observed covariates. Applying covariate balancing propensity score weighting to generate more consistent estimates of the treatment effect in the face of potential confounding also provides no evidence of any link between local news availability and the adoption of pro-social behaviors. This pattern holds across the models with and without time-based interactions.

My analysis also cannot account for whether increased newspaper volume is associated with county residents giving more attention to the local news. I assume that it does, but if this assumption is wrong, it breaks the causal link between news availability and behavior change. Furthermore, increased attention to local news may manifest in attention explicitly directed to reporting on basic facts about the virus's spread and not information about how and why to socially distance.

In the same vein, newspapers may make some production decisions that affect the relationship between newspaper availability and behavior change. For example, local news may not be adequately addressing the information needs of community members during this time, a condition that has been identified in pre-COVID-19 reporting [23, 24]. Furthermore, evidence suggests that in choosing whom they feature in their reporting on the pandemic, newspapers are producing politicized and polarized coverage of the crisis [25].

One particular example of how these production-decision effects may play out is the difference between rural counties that share and do not share a media market with a city. Those that do tend to have their local news coverage focused on the urban environment and its challenges. During the pandemic, this focus has led to increased coverage of the pandemic's risks, which in turn has led those in these rural counties sharing a media market with a city to be more likely to practice social distancing [26]. (However, the observed effects were still substantively small.)

Additionally, Google's reports note that, in some cases, the change in behavior reported is based on limited data. In these cases, we should assume that the estimates could change dramatically if more data could have been collected during the baseline window. Furthermore, counties with fewer newspapers are also more likely to be missing outcome observations, especially regarding staying at home. This association could bias results and pose a threat to validity. As more data, especially from additional sources, becomes available, these results should be tested to see if they replicate.

Altogether, these limitations are relatively minor. The analyses presented here are sufficiently powered, consider a reasonable set of potential confounders, and ultimately apply appropriate methods for causal inference. I find that, when controlling for pandemic and county de- 
mographic features, the relationship between local newspaper volume and behavior change is effectively zero in both the case of travel for retail or recreation purposes and time spent at home. By comparison, partisanship has a much larger effect in both cases.

As America continues to deal with the fallout of the COVID-19 pandemic, it will face new challenges to the regular social and civic functioning of the country. Local news could play an important role in the management and response to these specific challenges, given its ability to inform and mobilize members of the mass public. However, assuming that local newspapers are providing sufficient coverage of the pandemic and providing information on the recommended responses, the evidence presented here indicates that local news coverage is not sufficient to undo the politicization and polarization of issues and behavior.

But, this study should not be taken as evidence that local newspapers provide diminished civic benefits. Instead, this work should begin conversations about why those in healthy and robust local news economies did not change their behavior and what types of productionside changes could be implemented to promote future behavior change. In particular, future research should extend the findings presented here by considering the issue from an audience perspective - who is responsive to local news? - and from a production perspective - how can local news outlets better position their work to lead to pro-social outcomes? Developing behavioral insights in these specific areas could help develop a more robust and healthy information environment, undermining this study's pessimistic implications.

\section{Methods}

\section{Data}

I collected mobility data from Google's COVID-19 Mobility Reports [27]. These reports, published for a set of countries and regions, compare how the number of trips and the time spent in different types of locations have changed compared to a baseline period from January 3rd, 2020 to February 6th, 2020. Each report includes measures for locations classified as recreation or retail, groceries or pharmacies, parks, transit stations, work, and residential. Certain counties did not generate enough data, so Google did not report any values in those cases. The data used in this study cover each day from February 15th, 2020, and April 30th, 2020. Supplementary Figure 1 visualizes the distribution of days of mobility data available for each county.

I combined these mobility data with counts of the number of newspapers operating in each county. These counts were based on the University of North Carolina at Chapel Hill's School of Media and Journalism's Center for Innovation and Sustainability in Local Media's proprietary 
database of newspapers [5]. These data were initially collected in 2018 and verified using a variety of trade sources. ${ }^{1}$

The New York Times originally published the data about the number of cases and deaths in each county I used in this study [28]. The New York Times also originally published the data about the statewide stayat-home-orders and the dates they were issued that are used in this study [18].

I turned to the 2018 American Community Survey (ACS), accessed through the tidycensus package in $\mathrm{R}$, to collect county demographic measures. I combined these with data about food access from the Department of Agriculture [29] and 2012 population density estimates from ESRI [30]. Finally, I also operationalized the partisan lean for each county as each county's 2016 vote share for Hillary Clinton.

\section{Modeling}

To estimate the relationship between local news availability and mobility behavior changes during the COVID-19 pandemic, I estimated a series of linear models for the 'Retail \& recreation' and 'Residential' mobility data. The simplest models regressed the percentage-point change from baseline in standard-deviation units for the given category on the number of newspapers published in a county. I followed these models by estimating additional models, including controls for four COVID-19 related features: the number of cases on the given day, the number of deaths on the given day, the number of days since the beginning of the observation period, and a binary indicator for whether a statewide stayat-home order was in place. I also included the interaction between the binary stay-at-home-order indicator and the measure of days since the beginning of the time window to account for these orders' time-varying effects.

To account for further additional demographic and structural factors, I also estimated models with additional covariates, including those for the county's racial composition, the county's education level, poverty levels, internet access, food access, population density, and partisan lean. Since some of these covariates are likely confounders related to both local news availability and the response to the pandemic, I estimated a final set of models using non-parametric covariate balancing propensity score weighting [31]. This approach provides a less biased causal estimate of the effect of newspaper availability on change in mobility behavior. Supplementary Figure 2 visualizes the difference in the correlation between treatment and covariates before and after applying the weights generated through the balancing process.

\footnotetext{
${ }^{1}$ More information about the database and how it was constructed can be found on their website.
} 
To assess whether changes in the information about COVID-19 moderated local news effects, I estimated models with interactions between newspaper volume and time based on two major information interventions: the corresponding announcements on March 11th, 2020, that COVID-19 had reached a pandemic status, Tom Hanks had contracted the illness, and the NBA was suspending its season, and the subsequent implementations of stay-at-home orders by state governors. (These orders were put in place on different dates.) To account for the fact that the implementation of orders, the volume of local news available in a county, and the response variables all share causes, I also included controls for a county's number of reported COVID-19 cases and deaths, as well as the demographic and structural factors included in the earlier models. These models were also re-estimated using nonparametric covariate balancing propensity score weighting to account for potential confounding.

In all cases, the outcomes and continuous predictors were centered and standardized.

\section{Data Availability}

The figures and analyses in this paper are based on data provided by Google, the University of North Carolina at Chapel Hill's School of Media and Journalism's Center for Innovation and Sustainability in Local Media, The New York Times, ESRI, the United States Census, and United States Department of Agriculture. Processed minimal datasets necessary for reproducing analyses and figures, are available via the associated OSF repository for this project.

\section{Code Availability}

Original code, like data, is available via the associated OSF repository for this project. 


\section{References}

1. Shearer, E. Local news is playing an important role for Americans during COVID-19 outbreak July 2020. https: / /www.pewresearch. org/fact-tank/2020/07/02/local-news-is-playing-an-importantrole-for-americans-during-covid-19-outbreak/.

2. Koeze, E. \& Popper, N. The Virus Changed the Way We Internet Apr. 2020. www. nytimes . com / interactive / 2020/04 / 07 / technology / coronavirus-internet-use.html?searchResultPosition=1 .

3. Laslo, M. Coronavirus is revealing why local news is so important. It's also killing it. Apr. 2020. https: / /www.nbcnews.com/think/ opinion/ coronavirus-revealing-why-local-news-so-important-its-also-ncnal 186261.

4. Glaser, M. 6 Ways Local News Makes a Crucial Impact Covering COVID-19 Apr. 2020. https: / / knightfoundation.org/articles / 6ways-local-news-makes-a-crucial-impact-covering-covid-19/.

5. Abernathy, P. M. The Expanding News Desert research rep. (UNC: The Center for Innovation and Sustainability in Local Media, 2018).

6. Sullivan, M. Ghosting the News: Local Journalism and the Crisis of American Democracy (Columbia Global Reports, 2020).

7. Shaker, L. Dead newspapers and citizens' civic engagement. Political Communication 31, 131-148 (2014).

8. Gao, P., Lee, C. \& Murphy, D. Financing dies in darkness? The impact of newspaper closures on public finance. Journal of Financial Economics 135, 445-467 (2020).

9. Hayes, D. \& Lawless, J. L. The decline of local news and its effects: New evidence from longitudinal data. The Journal of Politics 80, 332-336 (2018).

10. Hayes, D. \& Lawless, J. L. As local news goes, so goes citizen engagement: Media, knowledge, and participation in US House Elections. The Journal of Politics 77, 447-462 (2015).

11. Van Green, T. \& Tyson, A. 5 facts about partisan reactions to COVID19 in the U.S. Apr. 2020. www.pewresearch.org/fact-tank/2020/ 04/02/5-facts-about-partisan-reactions-to-covid-19-in-the-u$\mathrm{s} /$.

12. Hughes, A., Shah, S. \& Smith, A. Tweets by members of Congress tell the story of an escalating COVID-19 crisis Apr. 2020. www. pewresearch.org/fact-tank/2020/04/02/tweets-by-members- ofcongress-tell-the-story-of-an-escalating-covid-19-crisis/. 
13. Jurkowitz, M. \& Mitchell, A. Cable TV and Coronavirus: How Americans perceive the outbreak and view media coverage differ by main news source Apr. 2020. www.journalism.org/2020/04/01/cabletv - and - covid - 19 - how - americans - perceive - the - outbreak- and view-media-coverage-differ-by-main-news-source/.

14. Druckman, J., Klar, S., Krupnikov, Y., Levendusky, M. \& Ryan, J. B. The Political Impact of Affective Polarization: How Partisan Animus Shapes COVID-19 Attitudes.

15. Brownstein, R. The Most Important 2020 States Already Have Vote by Mail Apr. 2020. https:/ /www.theatlantic.com/politics/archive/ 2020 / 04 / voting - mail - 2020 - race - between - biden - and - trump / $609799 /$.

16. Darr, J. P., Hitt, M. P. \& Dunaway, J. L. Newspaper closures polarize voting behavior. Journal of Communication 68, 1007-1028 (2018).

17. Trussler, M. Get Information or Get in Formation: The Effects of High-Information Environments on Legislative Elections. British Journal of Political Science, 1-21.

18. Mervosh, S., Lu, D. \& Swales, V. See Which States and Cities Have Told Residents to Stay at Home Mar. 2020. www. nytimes.com / interactive/2020/us/coronavirus-stay-at-home-order.html.

19. Shepardson, D. U.S. Senate deal does not extend assistance to local news outlets Apr. 2020. https: / / www. reuters.com / article / us health-coronavirus-usa-congress-media/u-s-senate-deal-doesnot-extend-assistance-to-local-news-outlets-idUSKCN223302.

20. Nielsen. In the 'New Normal' of COVID-19, Local TV News Proves to Be the Medium of Choice for News and Information Mar. 2020. https : / / www. nielsen. com / us / en / insights / article / 2020 / in the-new-normal- of-covid-19-local-tv-news- proves-to-be-themedium-of-choice-for-news-and-information/.

21. Koblin, J. The Evening News Is Back Mar. 2020. https:/ / www. nytimes.com/2020/03/24/business/media/coronavirus-eveningnews.html.

22. Grynbaum, M. M. Tucker Carlson Beats Sean Hannity as Trump Briefings Give Fox News a Boost Apr. 2020. https: / /www.nytimes. com/2020/04/28/business / media/virus-tucker-carlson-seanhannity-fox-ratings.html.

23. Napoli, P. M., Stonbely, S., McCollough, K. \& Renninger, B. Local journalism and the information needs of local communities: Toward a scalable assessment approach. Journalism Practice 11, 373-395 (2017). 
24. O'Keefe, J. \& Marby, J. Supporting Research on News Deserts. Facebook Journalism Project. facebookjournalismproject.com/article / supporting-research-on-news-deserts/ (Mar. 2019).

25. Hart, P. S., Chinn, S. \& Soroka, S. Politicization and Polarization in COVID-19 News Coverage. Science Communication.

26. Kim, E., Shepherd, M. E. \& Clinton, J. D. The effect of big-city news on rural America during the COVID-19 pandemic. Proceedings of the National Academy of Sciences 117, 22009-22014 (2020).

27. Fitzpatrick, J. \& DeSalvo, K. Helping public health officials combat COVID-19 Apr. 2020. www.blog.google/technology/health/covid19-community-mobility-reports.

28. Smith, M. et al. Coronavirus in the U.S.: Latest Map and Case Count Mar. 2020. www.nytimes.com/interactive/2020/us/coronavirusus-cases.html.

29. Service, U. E. R. Food access research atlas.

30. ESRI. USA Population Density data retrieved from ESRI, hub.arcgis. com/datasets/fab7849b55d54fof8f246605f6ee9306. 2013.

31. Fong, C., Hazlett, C., Imai, K., et al. Covariate balancing propensity score for a continuous treatment: Application to the efficacy of political advertisements. The Annals of Applied Statistics 12, 156177 (2018). 


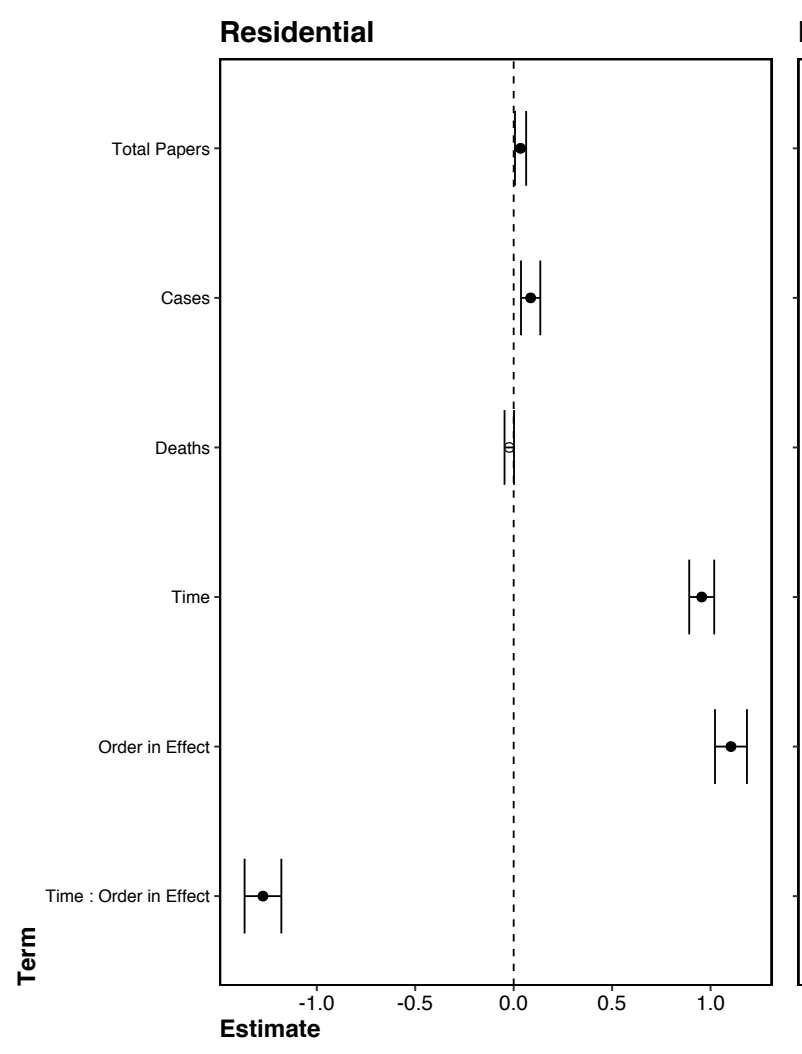

Retail and Recreation

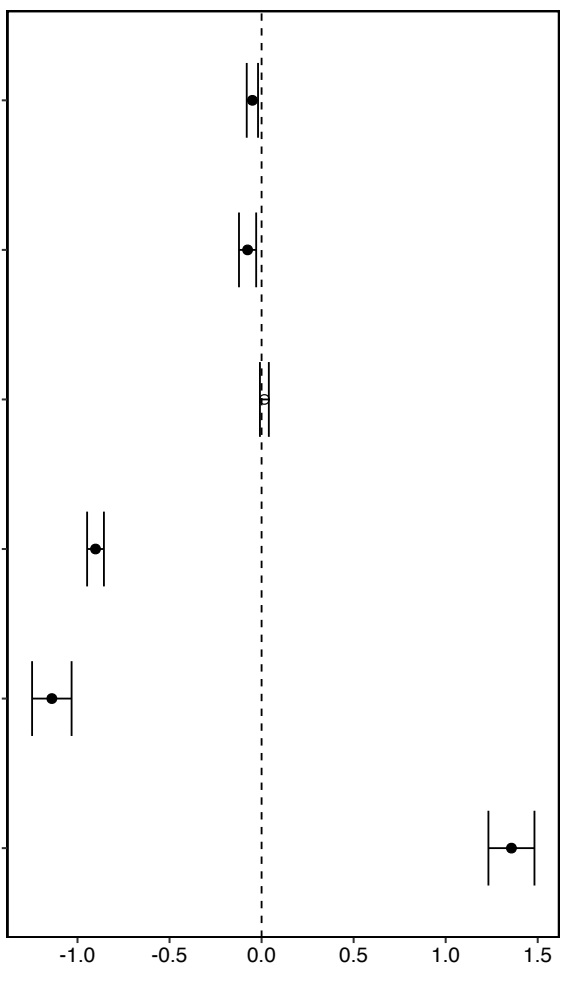

Figure 1: Regression coefficients estimated for models regressing mobility change on newspaper volume and pandemic features. Filled points indicate estimates that are statistically significant at the $\alpha=0.05$ level. Bars mark 95\% confidence intervals. Observations are at the county level. All continuous variables centered and standardized. Standard errors are clustered within counties and states. $N_{\text {Residential }}=81,019$ and $N_{\text {Retail }}=135,435$. 


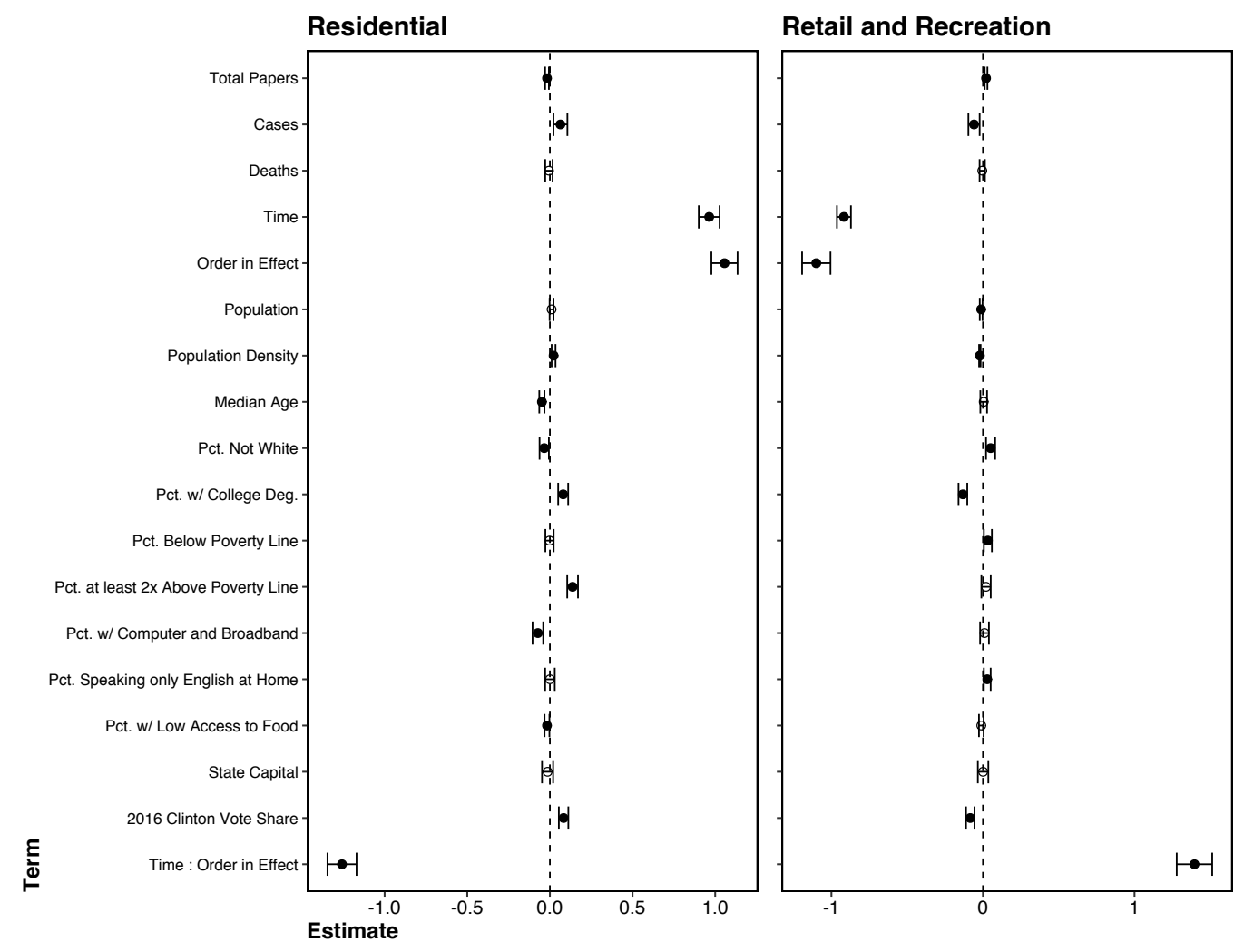

Figure 2: Regression coefficients estimated for models regressing mobility change on newspaper volume, pandemic features, and county demographic and structural measures. Filled points indicate estimates that are statistically significant at the $\alpha=0.05$ level. Bars mark 95\% confidence intervals. Observations are at the county level. All continuous variables centered and standardized. Standard errors are clustered within counties and states. $N_{\text {Residential }}=80,938$ and $N_{\text {Retail }}=135,287$. 


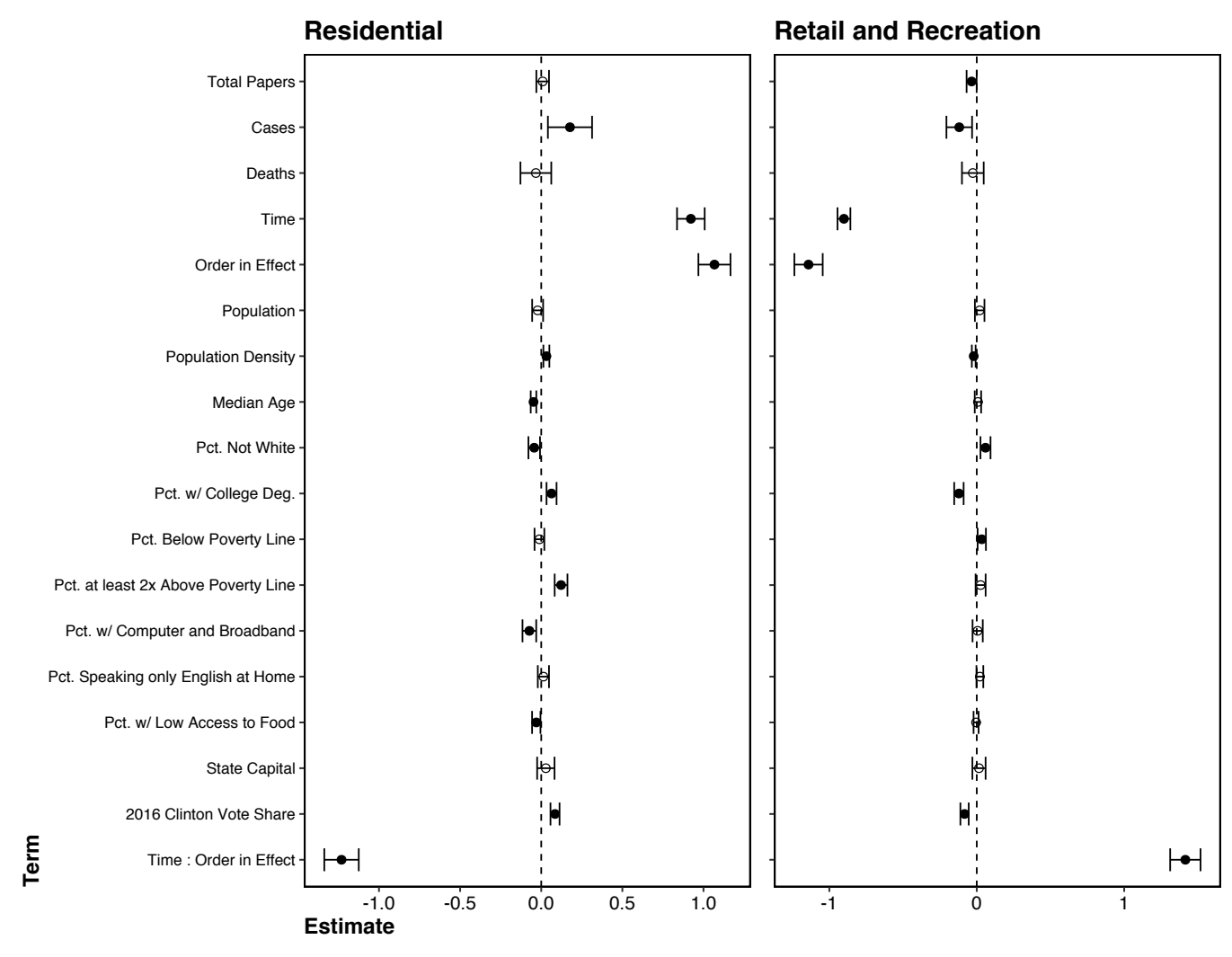

Figure 3: Regression coefficients estimated for models regressing mobility change on newspaper volume, pandemic features, and county demographic and structural measures. Filled points indicate estimates that are statistically significant at the $\alpha=0.05$ level. Bars mark 95\% confidence intervals. Observations weighted based on covariate balancing propensity score weighting. Observations are at the county level. All continuous variables centered and standardized. Standard errors are clustered within counties and states. $N_{\text {Residential }}=80,938$ and $N_{\text {Retail }}=135,287$ 
A. Staying Home - Unweighted

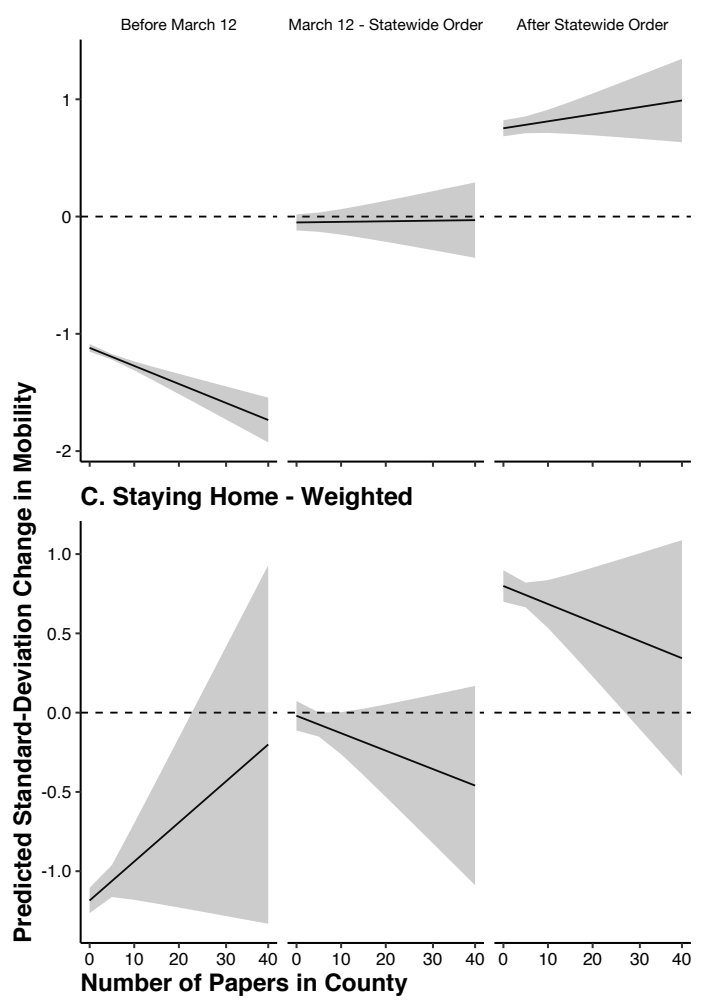

B. Travel for Retail or Recreation - Unweighted

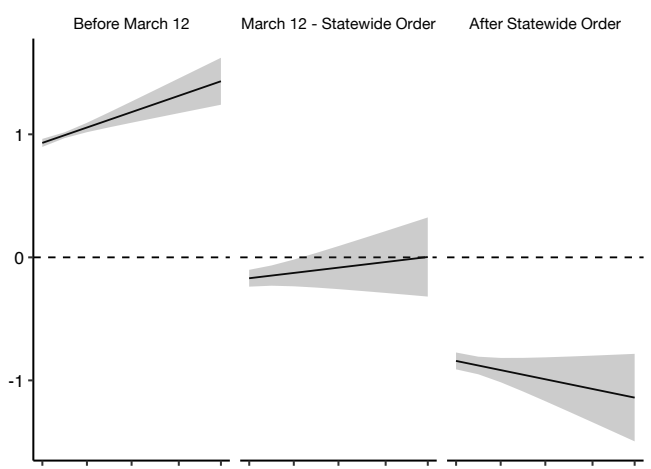

D. Travel for Retail or Recreation - Weighted

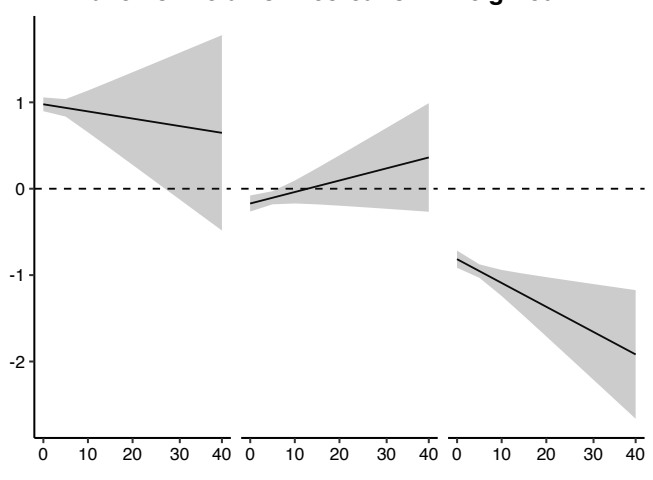

Figure 4: Predicted mobility change as the number of newspapers in a county increases across three time periods: Before March 12, between March 12 and the implementation of statewide orders, and after the implementation of statewide orders. Panels present results from different models. 


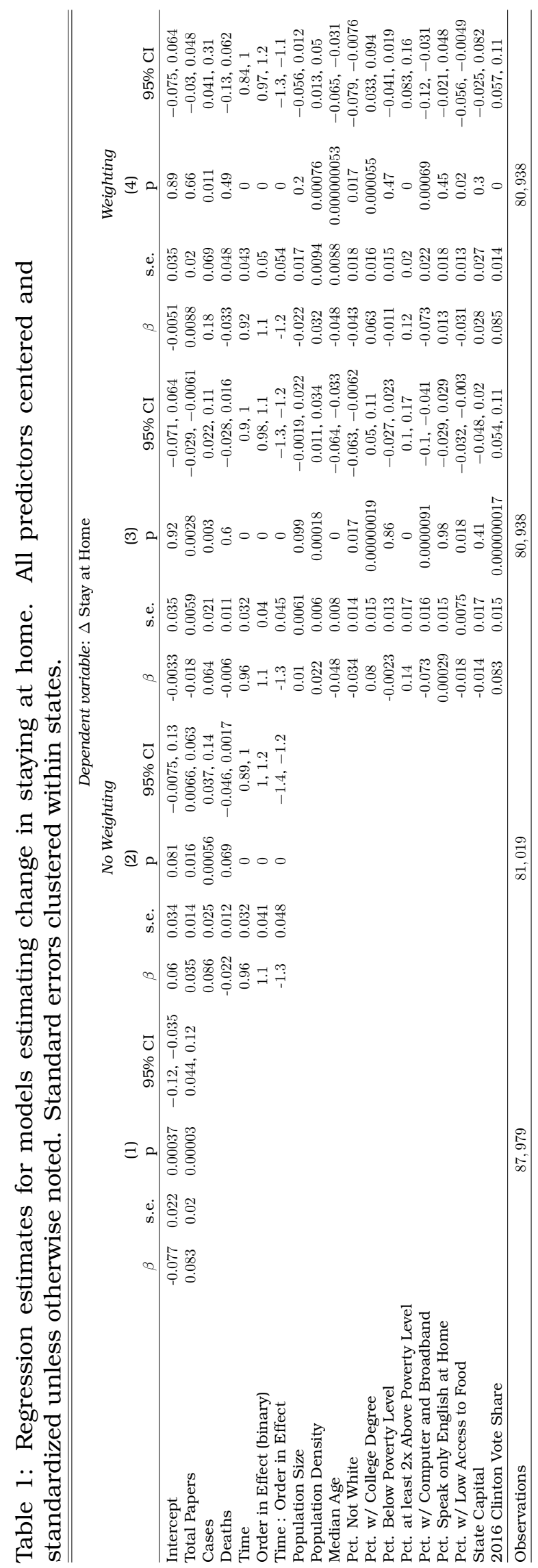




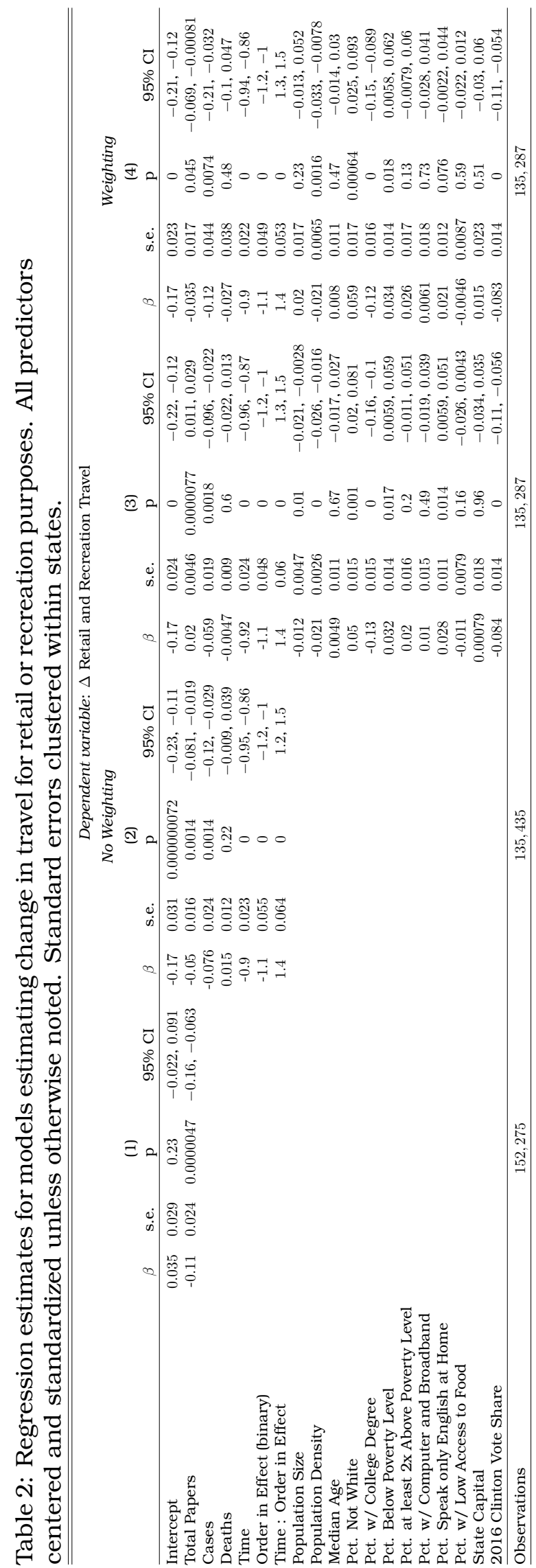


Table 3: Regression estimates for models estimating change in staying at home in three different time periods. All predictors centered and standardized unless otherwise noted. Standard errors clustered within states.

\begin{tabular}{|c|c|c|c|c|c|c|c|c|}
\hline & \multicolumn{8}{|c|}{ Dependent variable: $\Delta$ Stay at Home } \\
\hline & \multicolumn{4}{|c|}{ No Weighting } & \multicolumn{4}{|c|}{ Weighting } \\
\hline & \multicolumn{4}{|c|}{ (1) } & \multicolumn{4}{|c|}{ (2) } \\
\hline & $\beta$ & s.e. & $\mathrm{p}$ & $95 \% \mathrm{CI}$ & $\beta$ & s.e. & $\mathrm{p}$ & $95 \% \mathrm{CI}$ \\
\hline Intercept & -1.2 & 0.013 & 0 & $-1.2,-1.1$ & -1.1 & 0.026 & 0 & $-1.2,-1.1$ \\
\hline Total Papers & -0.053 & 0.0093 & 0 & $-0.071,-0.034$ & 0.084 & 0.052 & 0.11 & $-0.018,0.19$ \\
\hline March 12 - Statewide Order (binary) & 1.1 & 0.038 & 0 & $1,1.2$ & 1.1 & 0.043 & 0 & $1,1.2$ \\
\hline After Statewide Order (binary) & 1.9 & 0.038 & 0 & $1.8,2$ & 1.9 & 0.048 & 0 & $1.8,2$ \\
\hline Cases & 0.053 & 0.016 & 0.00089 & $0.022,0.085$ & 0.19 & 0.059 & 0.0015 & $0.072,0.3$ \\
\hline Deaths & -0.024 & 0.013 & 0.063 & $-0.048,0.0013$ & -0.082 & 0.039 & 0.036 & $-0.16,-0.0055$ \\
\hline Population Size & 0.0083 & 0.0062 & 0.18 & $-0.0039,0.02$ & -0.016 & 0.015 & 0.29 & $-0.047,0.014$ \\
\hline Population Density & 0.022 & 0.0067 & 0.001 & $0.0089,0.035$ & 0.031 & 0.0097 & 0.0012 & $0.012,0.05$ \\
\hline Median Age & -0.04 & 0.0082 & 0.00000085 & $-0.056,-0.024$ & -0.046 & 0.0085 & 0.000000056 & $-0.063,-0.03$ \\
\hline Pct. Not White & -0.025 & 0.015 & 0.095 & $-0.053,0.0043$ & -0.04 & 0.018 & 0.025 & $-0.076,-0.0052$ \\
\hline Pct. w/ College Degree & 0.083 & 0.016 & 0.0000001 & $0.052,0.11$ & 0.069 & 0.015 & 0.0000068 & $0.039,0.099$ \\
\hline Pct. Below Povtery Level & 0.00065 & 0.013 & 0.96 & $-0.025,0.026$ & -0.0091 & 0.015 & 0.54 & $-0.038,0.02$ \\
\hline Pct. at least $2 \mathrm{x}$ Above Poverty Level & 0.13 & 0.017 & 0 & $0.1,0.17$ & 0.12 & 0.019 & 0 & $0.086,0.16$ \\
\hline Pct. w/ Computer and Broadband & -0.075 & 0.016 & 0.0000043 & $-0.11,-0.043$ & -0.079 & 0.021 & 0.00018 & $-0.12,-0.038$ \\
\hline Pct. Speak only English at Home & -0.0031 & 0.015 & 0.84 & $-0.033,0.027$ & 0.014 & 0.017 & 0.43 & $-0.02,0.047$ \\
\hline Pct. w/ Low Access to Food & -0.019 & 0.0077 & 0.016 & $-0.034,-0.0035$ & -0.03 & 0.011 & 0.0068 & $-0.053,-0.0084$ \\
\hline State Capital & -0.02 & 0.017 & 0.23 & $-0.053,0.013$ & 0.02 & 0.025 & 0.42 & $-0.028,0.069$ \\
\hline 2016 Clinton Vote Share & 0.076 & 0.015 & 0.00000018 & $0.047,0.1$ & 0.082 & 0.015 & 0 & $0.054,0.11$ \\
\hline Total Papers : March 12 - Statewide Order (binary) & 0.054 & 0.02 & 0.0068 & $0.015,0.094$ & -0.12 & 0.071 & 0.085 & $-0.26,0.017$ \\
\hline Total Papers : After Statewide Order (binary) & 0.073 & 0.023 & 0.0016 & $0.028,0.12$ & -0.12 & 0.075 & 0.1 & $-0.27,0.024$ \\
\hline Observations & & & 83,578 & & & & 80,938 & \\
\hline
\end{tabular}


Table 4: Regression estimates for models estimating change in travel for retail and recreation purposes in three different time periods. All predictors centered and standardized unless otherwise noted. Standard errors clustered within states.

\begin{tabular}{|c|c|c|c|c|c|c|c|c|}
\hline & \multicolumn{8}{|c|}{ Dependent variable: $\Delta$ Retail and Recreation Travel } \\
\hline & \multicolumn{4}{|c|}{ No Weighting } & \multicolumn{4}{|c|}{ Weighting } \\
\hline & \multicolumn{4}{|c|}{ (1) } & \multicolumn{4}{|c|}{ (2) } \\
\hline & $\beta$ & s.e. & $\mathrm{p}$ & $95 \% \mathrm{CI}$ & $\beta$ & s.e. & $\mathrm{p}$ & $95 \% \mathrm{CI}$ \\
\hline Intercept & 0.960 & 0.012 & 0 & $0.93,0.98$ & 0.960 & 0.017 & 0 & $0.92,0.99$ \\
\hline Total Papers & 0.043 & 0.009 & 0.00000 & $0.025,0.061$ & -0.028 & 0.038 & 0.460 & $-0.1,0.046$ \\
\hline March 12 - Statewide Order (binary) & -1.100 & 0.025 & 0 & $-1.2,-1.1$ & -1.100 & 0.025 & 0 & $-1.1,-1.1$ \\
\hline After Statewide Order (binary) & -1.800 & 0.043 & 0 & $-1.9,-1.7$ & -1.800 & 0.050 & 0 & $-1.9,-1.7$ \\
\hline Cases & -0.044 & 0.011 & 0.0001 & $-0.065,-0.023$ & -0.110 & 0.031 & 0.0002 & $-0.17,-0.054$ \\
\hline Deaths & 0.023 & 0.010 & 0.029 & $0.0024,0.043$ & 0.064 & 0.020 & 0.002 & $0.024,0.1$ \\
\hline Population Size & -0.008 & 0.005 & 0.120 & $-0.018,0.0021$ & -0.0003 & 0.013 & 0.980 & $-0.027,0.026$ \\
\hline Population Density & -0.022 & 0.003 & 0 & $-0.029,-0.015$ & -0.023 & 0.004 & 0.00000 & $-0.031,-0.015$ \\
\hline Median Age & -0.004 & 0.010 & 0.710 & $-0.024,0.016$ & -0.001 & 0.011 & 0.900 & $-0.023,0.02$ \\
\hline Pct. Not White & 0.046 & 0.015 & 0.002 & $0.017,0.075$ & 0.063 & 0.017 & 0.0003 & $0.029,0.097$ \\
\hline Pct. w/ College Degree & -0.130 & 0.015 & 0 & $-0.16,-0.099$ & -0.120 & 0.017 & 0 & $-0.15,-0.086$ \\
\hline Pct. Below Povtery Level & 0.032 & 0.013 & 0.016 & $0.0058,0.057$ & 0.037 & 0.013 & 0.006 & $0.011,0.063$ \\
\hline Pct. at least $2 x$ Above Poverty Lev & 0.019 & 0.016 & 0.220 & $-0.011,0.05$ & 0.028 & 0.016 & 0.082 & $-0.0035,0.059$ \\
\hline Pct. w/ Computer and Broadband & 0.018 & 0.015 & 0.220 & $-0.011,0.047$ & 0.018 & 0.017 & 0.300 & $-0.016,0.051$ \\
\hline Pct. Speak only English at Home & 0.029 & 0.011 & 0.011 & $0.0066,0.051$ & 0.019 & 0.011 & 0.089 & $-0.0029,0.041$ \\
\hline Pct. w/ Low Access to Food & -0.010 & 0.008 & 0.190 & $-0.025,0.0048$ & 0.001 & 0.010 & 0.930 & $-0.018,0.02$ \\
\hline State Capital & 0.008 & 0.017 & 0.640 & $-0.026,0.042$ & 0.028 & 0.023 & 0.220 & $-0.017,0.073$ \\
\hline 2016 Clinton Vote Share & -0.079 & 0.014 & 0 & $-0.11,-0.052$ & -0.083 & 0.014 & 0 & $-0.11,-0.056$ \\
\hline Total Papers : March 12 - Statewide Order (binary) & -0.028 & 0.020 & 0.160 & $-0.067,0.011$ & 0.074 & 0.062 & 0.240 & $-0.048,0.2$ \\
\hline Total Papers : After Statewide Order (binary) & -0.068 & 0.020 & 0.001 & $-0.11,-0.029$ & -0.066 & 0.046 & 0.150 & $-0.16,0.023$ \\
\hline Observations & \multicolumn{4}{|c|}{142,388} & \multicolumn{4}{|c|}{135,287} \\
\hline
\end{tabular}

